\title{
Bilateral Aurikular Milia en Plak Bilateral Auricular Milia en Plaque
}

\section{Savaș Öztürk, Perihan Öztürk*, Müge Sezen**, Cahit Polat***}

Elazığ Eğitim ve Araștırma Hastanesi, Deri ve Zührevi Hastalıklar Kliniği ve ***Kulak Burun Boğaz Kliniği, Elazığ, Türkiye *Sütçü İmam Üniversitesi Tıp Fakültesi, Deri ve Zührevi Hastalıklar Anabilim Dalı, Kahramanmaraș, Türkiye **Elazığ Harput Devlet Hastanesi, Patoloji Kliniği, Elazı̆̆, Türkiye

\section{Özet}

Milia en plak (MEP) eritemli zemin üzerinde multipl milia benzeri kistlerle karakterize ve histolojik olarak multipl keratin kistleri özelliği gösteren son derece nadir bir milia formudur. Etyolojisi tam olarak bilinmemektedir. Genellikle orta yaș kadınlarda ve özellikle baș-boyun bölgesinde görülür. Tanımlanan vakaların çoğu daha çok retroauriküler bölge, göz kapakları ve burun bölgesine lokalizedir. Literatürde aurikula içinde tanımlanan olgu bulunmamaktadır. Bu yazıda 71 yașında kadın hastada aurikula içinde dıș kulak kanalında klinik ve histopatolojik olarak tanımlanan bilateral milia en plak olgusu güncel literatür bilgileriyle sunulmuștur. (Türkderm 2011; 45: 216-8)

Anahtar Kelimeler: Milia en plak, aurikula

\section{Summary}

Milia en plaque (MEP) is an extremely rare form of milia that is characterized by a number of milia-like cysts on an erythematous base and histologically exhibits features of keratin cysts. The etiology is not exactly known. MEP is generally seen among middle-aged women and especially on the head and neck region. Many of the diagnosed cases are localized in the retroauricular region, eyelids and the nose region. To date, no case of MEP in the auricula has been reported in the literature. In this article, we present the case of a 71-year-old female patient clinically and histologically diagnosed with bilateral auricular milia en plaque (in the external ear canal) in the light of current literature. (Turkderm 2011;45: 216-8)

Key Words: Milia en plaque, auricula

\section{Giriş}

Milia en plak (MEP) daha çok orta-ileri yaş kadınlarda, başboyun bölgesinde eritemli zemin üzerinde gelişen keratin kistleri ile karakterize çok nadir inflamatuvar bir milia varyantıdır., En fazla yerleşim yerleri retroaurikuler alanlar, burun kanatları, supraklavikuler alanlar, göz kapakları, periorbital bölge ve alındır.2- Etyolojisi tam bilinmemekle birlikte bazen lokal irritasyon sonucu, kozmetik etkili kremlere ya da topikal steroid kullanımlarına bağlı gelişebileceği bildirilmiştir. Histopatolojik olarak küçük keratin dolu kistler ve etrafında yoğun lenfositik infiltrat bulunur ${ }^{1,2}$. Kozmetik açıdan sorun olabilen bu durumda tedavide kimyasal eksfolyanlar, retinoik asit uygulaması, kriyoterapi, koterizasyon ve manuel ekstirpasyon denenebilir'1.

\section{Olgu}

Her iki kulak kepçesinde sarı kabarıklıklar olması yakınması ile dermatoloji polikliniğine başvuran 71 yaşındaki bayan

Yazışma Adresi/Address for Correspondence: Dr. Savaș Öztürk, Elazı̆̆ Eğitim ve Araștırma Hastanesi Deri ve Zührevi Hastaliklar Kliniği, Elazıı̆, Türkiye Tel.: +90 4242381000 E-posta: drsozturk@windowslive.com Geliş Tarihi/Received: 28.08.2010 Kabul Tarihi/Accepted: 06.12.2010

Türkderm-Deri Hastalıkları ve Frengi Arșivi Dergisi, Galenos Yayınevi tarafından basılmıștır. Turkderm-Archives of the Turkish Dermatology and Venerology, published by Galenos Publishing. 
hasta değerlendirildi. Öyküsünde daha önce kulak burun boğaz polikliniğinde ksantalezma ön tanısı ile takip edildiği, lezyonların yaklaşık bir yıldır olduğu, öncesinde travma, topikal steroid kullanımı olmadığı, ailesinde benzer yakınmaları olan kimse bulunmadığı ve kendisinde ve ailesinde romatolojik hastalık olmadığı öğrenildi. Rutin hematolojik ve biyokimyasal tetkiklerde ve lipit profilinde herhangi anomali saptanmayan hastanın yapılan muayenesinde her iki kulak kepçesinde antiheliksten dış kulak kanalına kadar olan alanda hafif eritemli zeminde çok sayıda 1-3 mm çapta sarı renkte ve gergin duvarlı küçük kistik yapılar saptandı (Resim 1-2). Kulak zarı muayenesi normal olan hastanın lezyonlarından alınan eksizyonel biyopsi materyalinin histopatolojik incelemesinde granüler tabakası belirgin çok katlı yassı epitelle döşeli küçük kistik yapılar ve bu kistlerin içinde lameller tarzda birikim gösteren keratin mevcuttu (Resim 3-4). Klinik ve histopatolojik bulgularıyla MEP tanısı konulan ve subjektif yakınmaları olmayan hastaya klinik takip önerildi.

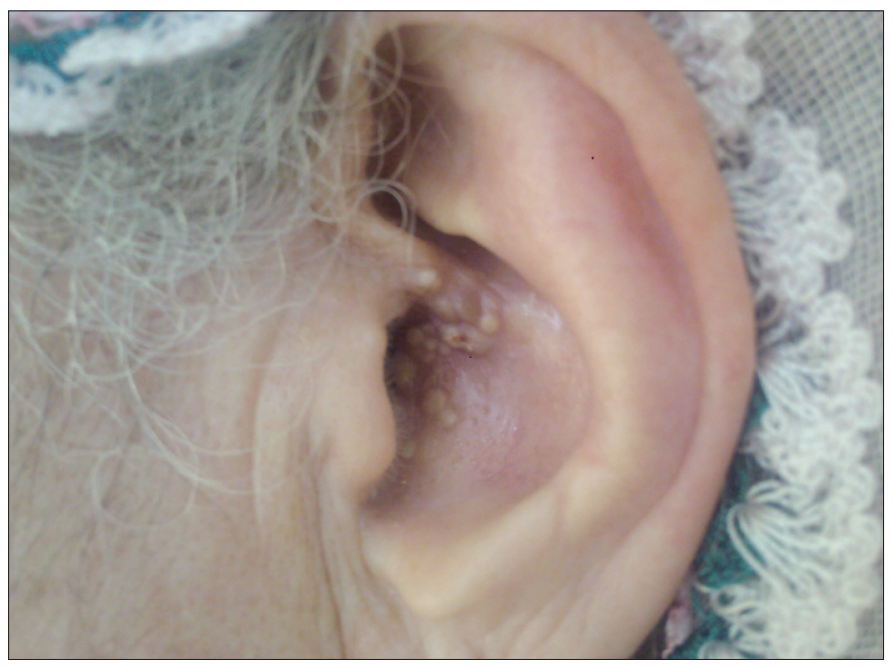

Resim 1. Olgunun klinik görünümü

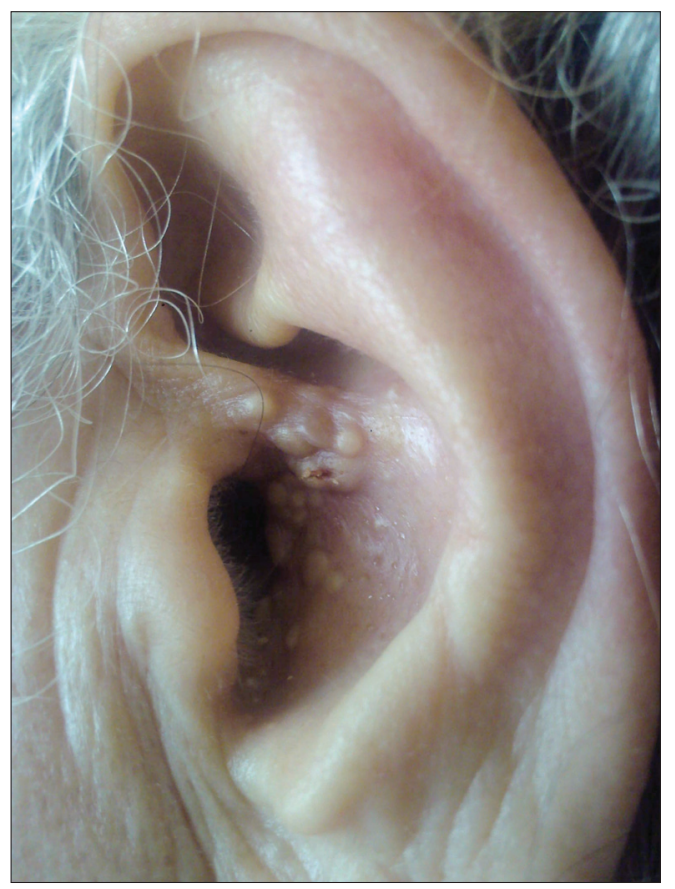

Resim 2. Olgunun yakın plandan klinik görünümü

\section{Tartışma}

MEP hafif eritemli zemin üzerine yerleşen küçük keratin kistleri ile karakterize çok nadir görülen bir milia şeklidir. En sık orta-ileri yaşta ve ağırlıklı olarak kadınlarda görülür ${ }^{1.4}$. Literatürde az sayıda çocukluk çağında görülen olgu bildirileri mevcuttur ${ }^{4}$. En sık yerleşim yeri retroaurikuler alan olmakla birlikte periaurikuler, periorbital, supraklavikuler ve submandibuler bölgeler ile burun, göz kapakları ve alında da ortaya çıkabilir ${ }^{5.7}$. Genelde etyolojik faktör saptanamaz. Bununla birlikte lokal travmaların, topikal steroid ve kozmetik ürün kullanımlarının, iyonizan radyasyon uygulamalarının, gözlük camlarının neden olabileceği rapor edilmiştir. ${ }^{1-3}$ Lupus eritematosus, liken planus, pseudoksantoma elastikum gibi hastalıkların MEP veya MEP benzeri lezyonlara yol açabileceği belirtilmiştir. ${ }^{18,9}$ Miliada histopatolojik incelemede içi keratin dolu kistler ve çevrede lenfositik infiltrat görülmektedir¹.

Literatür incelendiğinde en fazla retroaurikuler yerleşimli olgular bildirilmiştir, bunun yanında supraklavikuler, göz kapağı, alın, periorbital yerleşimli olguların olduğu görülmüştür. Yine literatür tarandığında MEP'in aurikuler alanda veya dış kulak kanalında tariflenmediği görülmektedir. Tanımlanan vakaların çoğu 4-6. dekatta olmakla birlikte lite-

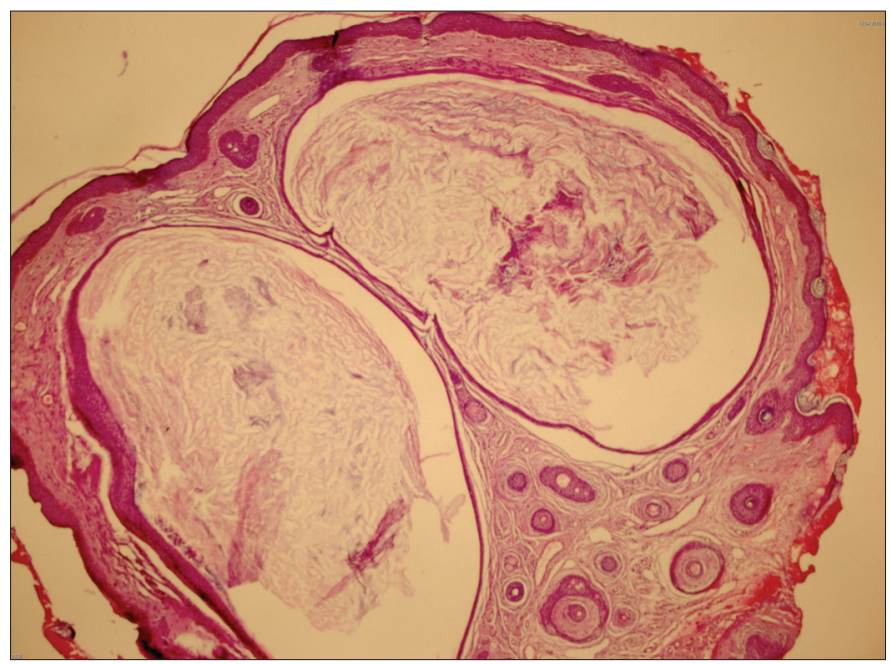

Resim 3. Keratin kistleri (HEX40 büyütme)

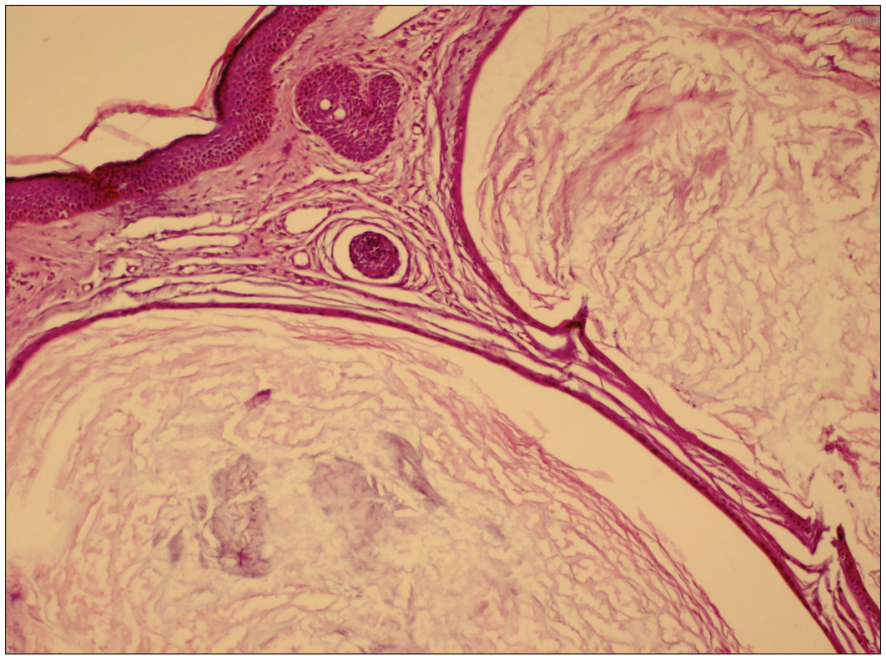

Resim 4. Keratin kistleri içinde lameller tarzda biriken keratin (HEX200 büyütme) 
ratürde dört pediyatrik olgu tariflenmiştir. ${ }^{4}$ Bildirilen beş olgu lupus eritematosusla, bir olgu psödoksantoma elastikumla ilişkili bulunmuştur. Tariflenen diğer olgularda herhangi bir internal hastalıkla ilişki saptanamamıştır. MEP'in tedavisinde etretinat, elektrokoterizasyon, dermabrasyon, CO2 laser, kriyoterapi, lokal fotodinamik tedavilerin kullanıldığı ve başarılı olduğunu belirten yayınlar bulunmaktadır. ${ }^{3,10}$ Hastamızın ileri yaşta olması ve lezyonların herhangi bir yakınmaya sebep olmaması nedeniyle tedavisi planlanmamıştır.

\section{Kaynaklar}

1. Hallaji Z, Akhyani M, Jamshidi S, Modabbernia A, Kamyab K: Bilateral retro-auricular milia en plaque: A case report and review of the literature. Dermatol Online J 2010;16:12.

2. Ergin S, Başak P, Sari A: Milia en plaque. J Eur Acad Dermatol Venereol 2000;14:47-9.
3. Stefanidou MP, Panayotides JG, Tosca AD: Milia en plaque: a case report and review of the literature. Dermatol Surg 2002;28:291-5.

4. Sinagra J, Donati P, Amantea A: Milia en plaque: three new pediatric cases. Cota C. Pediatr Dermatol 2009;26:717-20.

5. Kautz $O$, Muller $S$, Braun-Falco $M$, Nashan D: Milia en plaque in a linear pattern. J Eur Acad Dermatol Venereol 2009;23:1335-6.

6. Fujita $H$, Iguchi $M$, Kenmochi $Y$, Fukunaga $Y$, Asahina $A$ : Milia en plaque on the forehead. J Dermatol 2008;35:39-41.

7. Wollina U: Bilateral milia en plaque of the eyelids: long eyelashes and unibrow-case report and review of literature. Dermatol Surg 2010;36:406-8.

8. Belhadjali H, Youssef M, Yahia S, Njim L, Zakhama A, Zili J: Milia en plaque and discoid lupus erythematosus. Clin Exp Dermatol 2009;34:356-7.

9. Rose RF, Merchant W, Goulden V: Retroauricular milia en plaque: a rare presentation of lupus erythematosus. Clin Exp Dermatol 2008;33:715-7.

10. Ishiura $\mathrm{N}$, Komine $\mathrm{M}$, Kadono $\mathrm{T}$, Kikuchi $\mathrm{K}$, Tamaki $\mathrm{K}$ : A case of milia en plaque successfully treated with oral etretinate. $\mathrm{Br} J$ Dermatol 2007;157:1287-9. 